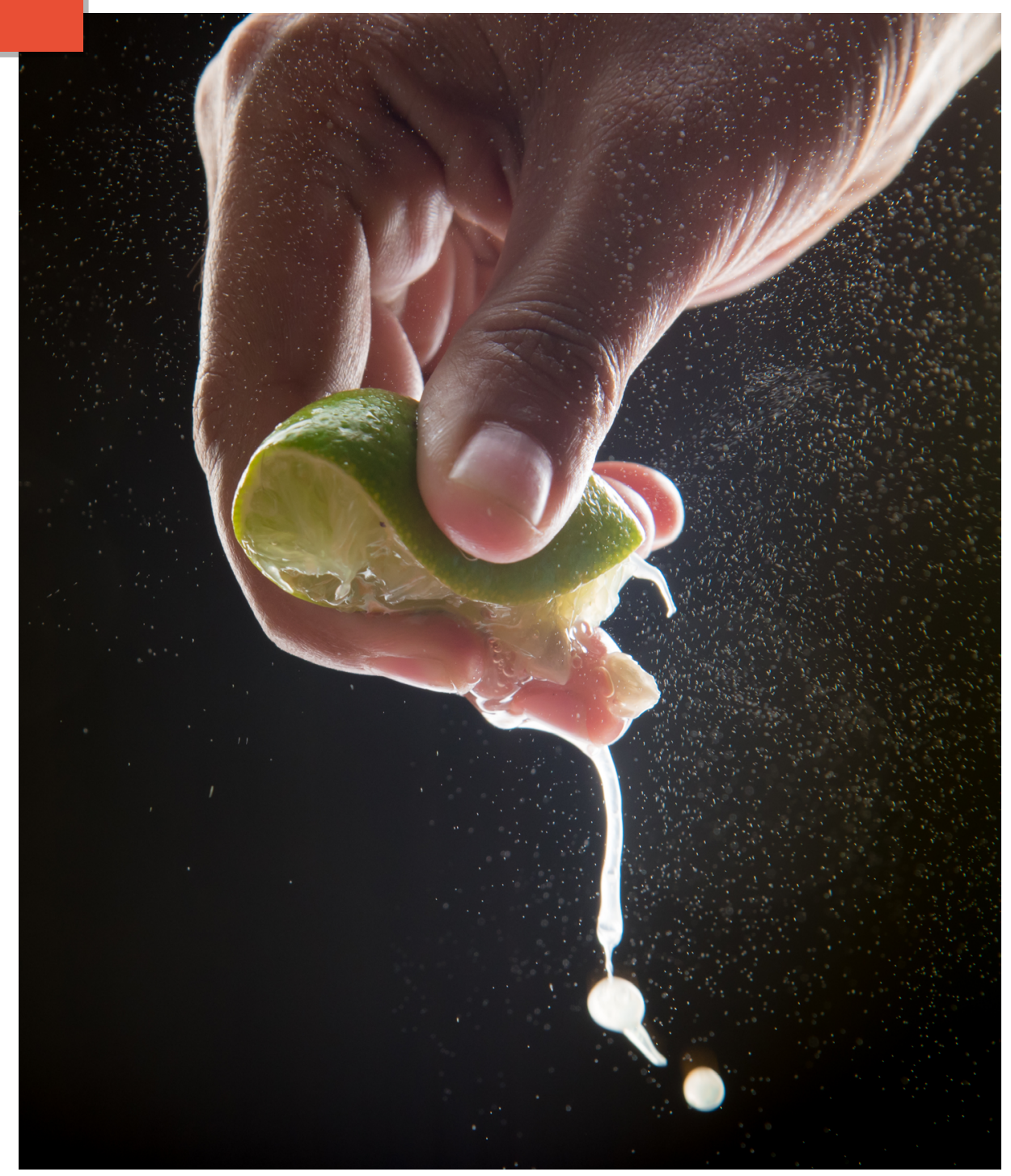

\title{
DE UM LIMÃO, UMA LIMONADA
}

GOVERNOS, ORGANIZAÇÕES NÃO GOVERNAMENTAIS (ONGS), GRANDES EMPRESAS E STARTUPS VÊM MOSTRANDO QUE É POSSÍVEL TER GANHOS FINANCEIROS, AMBIENTAIS E SOCIAIS AO DIMINUIR AS PERDAS QUE OCORREM COM ALIMENTOS DESDE A PRODUÇÃO ATÉ O CONSUMO.

| POR DANIELE ECKERT MATZEMBACHER, MARCIA DUTRA DE BARCELLOS E LUCIANA MARQUES VIEIRA 


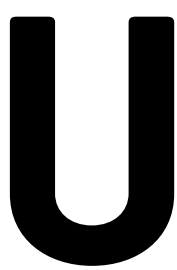

$\mathrm{m}$ terço dos alimentos produzidos no mundo é perdido ou desperdiçado ao longo da cadeia de produção e de consumo, de acordo com a Organização das Nações Unidas para a Alimentação e a Agricultura (FAO, na sigla em inglês). Esse é um problema ambiental, econômico e social relevante que se agravará nos próximos anos. Com a expectativa de que a população mundial, avaliada em quase 7,6 bilhões em meados de 2017, atinja o número de 10 bilhões de pessoas em 2050 (70\% urbana, contra os $49 \%$ da proporção atual), haverá necessidade de aumento de $70 \%$ na produção de alimentos, segundo a FAO.

Considerando esse cenário, reduzir o desperdício de comida entrou na agenda tanto do setor público como do setor privado. Gestores de políticas públicas, movimentos de organizações da sociedade civil e empreendedores vêm enfrentando o desafio de encontrar soluções para diminuir as perdas no setor.

\section{MOVIMENTO DE COMBATE AO DESPERDÍCIO}

Até o presente momento, não há um marco regulatório aprovado no Brasil que trate sobre o desperdício de alimentos, no entanto existem indícios de que o governo está se mobilizando para isso. Há alguns meses, foi lançada a Estratégia Intersetorial para a Redução de Perdas e Resíduos de Alimentos no Brasil. É uma iniciativa liderada pela Câmara Interministerial de Segurança Alimentar e Nutricional (CAISAN), com a participação de órgãos públicos, organizações não governamentais (ONGs), universidades, FAO e associações da indústria, das centrais de abastecimento e dos supermercados.

O propósito é coordenar ações para prevenir e reduzir as perdas e o desperdício de alimentos no Brasil em 50\% até 2030, por meio da gestão mais integrada e intersetorial de iniciativas do governo e da sociedade. A estratégia é composta de sete objetivos: fomentar a realização de pesquisas que auxiliem na determinação das causas e de soluções; estimular a inovação tecnológica e social para o tema; contribuir para o desenho de metodologia de quantificação do desperdício no Brasil; participar das discussões sobre a temática no país e no exterior; apoiar ações de comunicação e divulgação de boas práticas perante a população; fortalecer e aprimorar as políticas públicas relacionadas ao tema; e propor alterações nos marcos legais e apoiar a aprovação de projetos de lei, de forma a aperfeiçoar o fluxo da doação de alimentos.

Além disso, várias iniciativas para o problema do desperdício de alimentos surgem de organizações da sociedade civil.

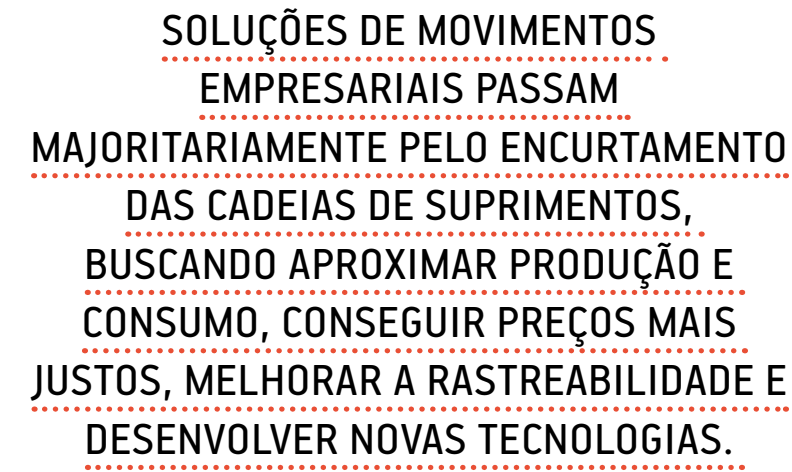

No ambiente acadêmico, destacam-se grupos e projetos de pesquisa desenvolvidos pela Escola de Administração de Empresas de São Paulo da Fundação Getulio Vargas (FGV EAESP), Universidade Federal de São Carlos (UFSCar) e Universidade Federal do Rio Grande do Sul (UFRGS), em parcerias com governo, diversos elos de cadeias de suprimentos, Empresa Brasileira de Pesquisa Agropecuária (Embrapa), ONGs e parceiros internacionais. De modo geral, os projetos desenvolvidos tratam da perda de alimentos numa perspectiva de economia circular, buscando formas de reinserir os alimentos que seriam desperdiçados nas cadeias de suprimentos mediante novos modelos de negócios ou novas práticas gerenciais, e/ou investigando meios de conscientizar os indivíduos e incentivar o consumo total dos alimentos.

Com apoio institucional da FAO, a Save Food Brasil é uma iniciativa liderada por Embrapa, World Resources Institute (WRI) Brasil e World Wide Fund for Nature (WWF) Brasil que procura montar uma rede nacional para a redução das perdas e de desperdício de alimentos no Brasil. Uma das sugestões é para as organizações realizarem uma Semana de Desperdício de Alimentos. A Save Food Brasil argumenta que essa é uma maneira de envolver os funcionários na redução do desperdício de alimentos e de promover atividades de formação de equipes, como o trabalho voluntário em um banco de alimentos ou uma excursão de campo.

As mesmas instituições - FAO, Embrapa, WRI e WWF lançaram a campanha \#SemDesperdício, com os objetivos de ampliar a consciência dos brasileiros sobre o desperdício de alimentos e ajudar a mudar hábitos de consumo alimentar. Entre as ações, estão dicas (como planejar a aquisição de comida em eventos, promover prêmios e concursos no ambiente de trabalho e tomar cuidado com a compra, o armazenamento e o consumo de alimentos em casa) e desafios (internautas que incorporaram dicas da campanha de 


\section{PERDA OU DESPERDÍCIO DE ALIMENTOS PER CAPITA NO CONSUMO}

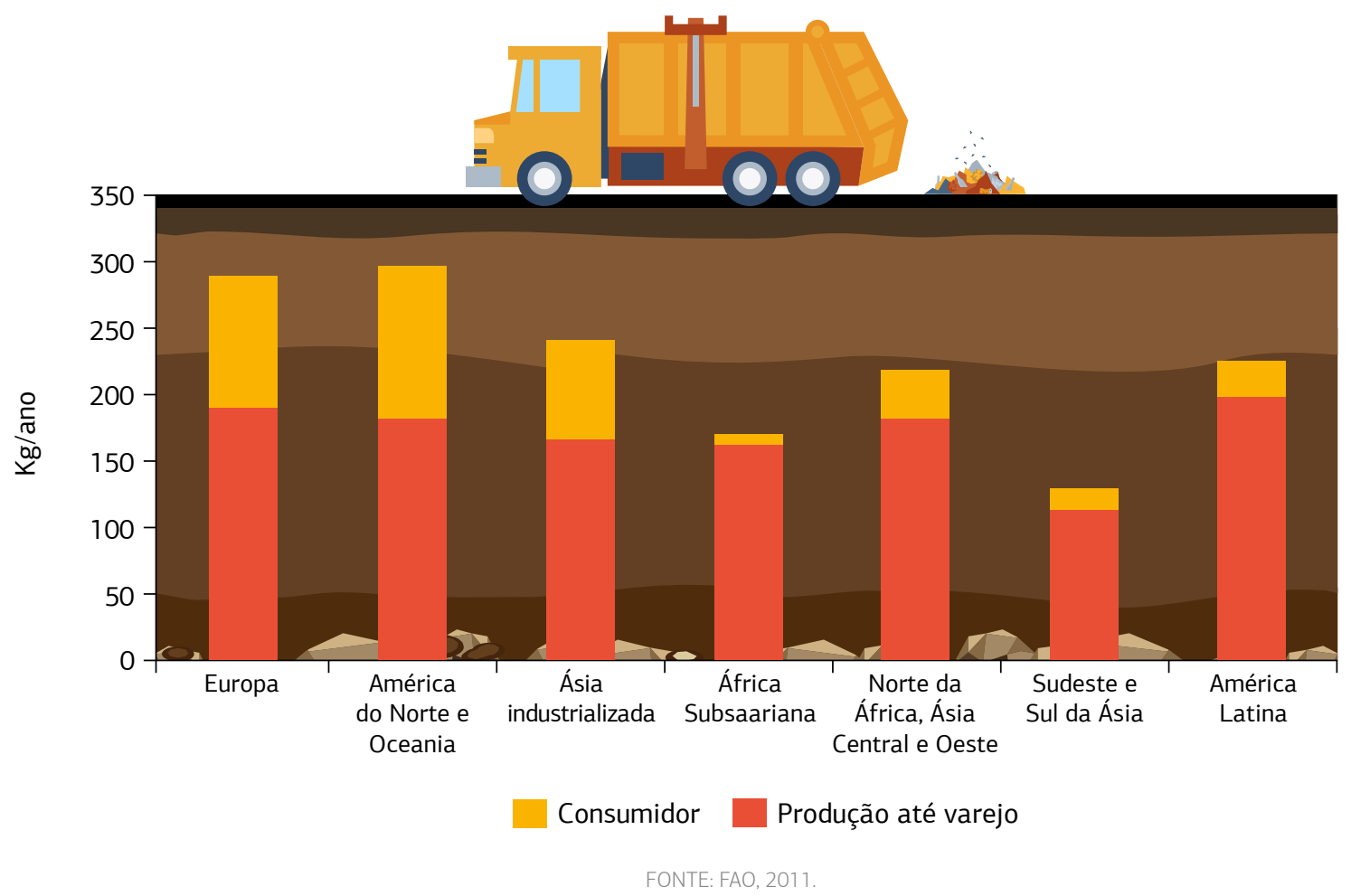

como adotar hábitos de consumo mais sustentáveis ganharam camisetas da iniciativa).

No setor privado, destaca-se a Foodtech Movement. O intuito é incentivar a discussão sobre o setor alimentos e sustentabilidade, criando condições favoráveis para que empreendedores e novos negócios possam se desenvolver. O movimento incorpora o conceito de food system, fortalecendo a importância da colaboração e parceria entre organizações, universidades, indústrias e startups para a inovação sustentável. As soluções discutidas passam majoritariamente pelo encurtamento das cadeias de suprimentos, buscando aproximar produção e consumo, conseguir preços mais justos, melhorar a rastreabilidade e desenvolver novas tecnologias.

Por exemplo, uma solução desenvolvida que foi apresentada em evento do Foodtech Movement é a Made in Farm, uma plataforma de compra e venda de cafés que aproxima o agricultor e as cooperativas do público urbano, oferecendo soluções de rastreabilidade e de comércio justo. Dessa forma, o consumidor tem acesso à informação geográfica, à variedade do grão, ao nome do produtor e paga menos
AS FOOD TECHS TRANSFORMAM O PROBLEMA DE DESPERDÍCIO EM UMA OPORTUNIDADE DE NEGÓCIO, AO UTILIZAREM TECNOLOGIA PARA INOVAR DESDE A PRODUÇÃO ATÉ A ENTREGA DOS ALIMENTOS AOS CONSUMIDORES FINAIS.

com a retirada de intermediários da cadeia de distribuição. O produtor, por sua vez, recebe uma remuneração maior e tem o seu trabalho reconhecido.

O grande desafio que esse movimento de combate ao desperdício de alimentos enfrenta é trabalhar com a complexidade de agentes envolvidos nas cadeias de suprimentos do setor de alimentos. Além disso, o setor precisa lidar com questões relacionadas a assimetrias de poder na coordenação, somadas muitas vezes a longas distâncias geográficas e a questões comportamentais. Entretanto, há forte expectativa de que, com amplo engajamento, haverá resultados positivos refletidos na regulamentação e nas políticas públicas. 


\section{AO ANALISAR INICIATIVAS DE 1.200 EMPRESAS EM 17 PAÍSES, O WRI DESCOBRIU QUE 99\% DAS ORGANIZAÇÕES OBTIVERAM RETORNO POSITIVO SOBRE O INVESTIMENTO, E A METADE ALCANÇOU RETORNO FINANCEIRO 14 VEZES MAIOR SOBRE O VALOR INVESTIDO.}

\section{NOVO MERCADO PARA \\ ALIMENTOS DESPERDIÇADOS}

Há também iniciativas empreendedoras que transformam o problema do desperdício de alimentos em uma oportunidade de negócio capaz de gerar valor econômico, social e ambiental. São as food techs, que utilizam tecnologia para inovar desde a produção até a entrega dos alimentos aos consumidores finais.

Em São Paulo, startups vêm criando um novo mercado para alimentos que seriam desperdiçados ou jogados no lixo. Uma delas, a Fruta Imperfeita, funciona por meio de uma plataforma digital para que os consumidores associados recebam cestas com alimentos "imperfeitos" - que seriam descartados pelos produtores ou porque a colheita excedeu a demanda ou porque a sua aparência não atende ao alto padrão estético exigido pelo varejo e pelos consumidores. A empresa iniciou suas operações em 2015 com cerca de 10 clientes e hoje tem 1.200 .

Outro negócio, Laranjas Online, começou depois que a fundadora observou que parte das laranjas produzidas na fazenda da família estava sendo descartada, já que as indústrias de suco estavam com excesso de oferta. Então, começou a vender laranjas no Facebook. Depois, montou uma plataforma digital para se conectar com os clientes restaurantes, escolas, clubes e consumidores finais. Todos os produtos colhidos são enviados aos clientes, desde que estejam aptos ao consumo. Cabe destacar também o Ndays Consumo Imediato, uma plataforma on-line que disponibiliza a consumidores finais e pessoas jurídicas produtos que estão próximo da data de validade, a um preço inferior ao do mercado - de alimentos a produtos eletrônicos.

\section{UM NEGÓCIO GANHA GANHA}

Os resultados de ações de redução do desperdício de alimentos mostram-se promissores. Levantamento recente do WRI analisou iniciativas em cerca de 1.200 empresas em 17 países. Verificou-se que $99 \%$ das organizações obtiveram retorno positivo sobre o investimento, e a metade alcançou retorno financeiro 14 vezes maior sobre o valor investido. Resultados similares foram verificados em iniciativas nacionais. O Reino Unido, por exemplo, reduziu o desperdício de alimentos do consumidor final em $21 \%$ entre 2007 e 2012 com articulação entre governo, varejistas e a ONG WRAP. Além disso, para cada 1 libra investida nos esforços, as famílias e as autoridades locais economizaram 250 libras. A atuação das food techs também mostra como é possível gerar valor ao incorporar práticas mais sustentáveis na operação e na estratégia de negócios.

Além do resultado financeiro positivo para consumidores, empresas e administração pública, as ações voltadas ao desperdício de alimentos geram benefícios ambientais e sociais. Há estudos indicando impactos positivos em conservação de solo, energia, água e recursos utilizados na agricultura, além da diminuição de poluição atmosférica. Do ponto de vista social, reduzir o desperdício de alimentos fortalece o combate à fome e aumenta a segurança alimentar.

Os impactos positivos fundamentam a possibilidade de ações de redução de perdas e desperdícios de alimentos em todas as esferas sociais. Nesse sentido, os futuros empreendedores precisam estar atentos às oportunidades que o mercado oferece e tomar como exemplo as inovadoras soluções que surgem, como as food techs. Há também a possibilidade de atuar por meio de medidas gerenciais e de políticas de gestão socioambiental, fortalecendo os resultados financeiros, ambientais e sociais das organizações.
PARA SABER MAIS:

Organização das Nações Unidas para a Alimentação e a Agricultura (FAO). Global Food Losses and Food Waste - Extent, Causes and Prevention, 2011;

Câmara Interministerial de Segurança Alimentar e Nutricional. Estratégia Intersetorial para a Redução de Perdas e Desperdício de Alimentos no Brasil, 2018. Disponivel em: mds.go

Foodtech Movement no Brasil. Disponivel em:

Save Food Brasil. Disponível em:

DANIELE ECKERT MATZEMBACHER > Doutoranda em Administração na UFRGS > daniele.eckert@ufrgs.br

MARCIA DUTRA DE BARCELLOS > Professora na Escola de Administração da UFRGS > marcia.barcellos@ufros.br

LUCIANA MARQUES VIEIRA > Professora da FGV EAESP > luciana.vieira@fgv.br 